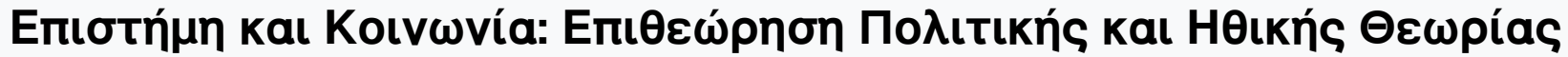

Tó 14 (2005)

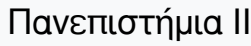

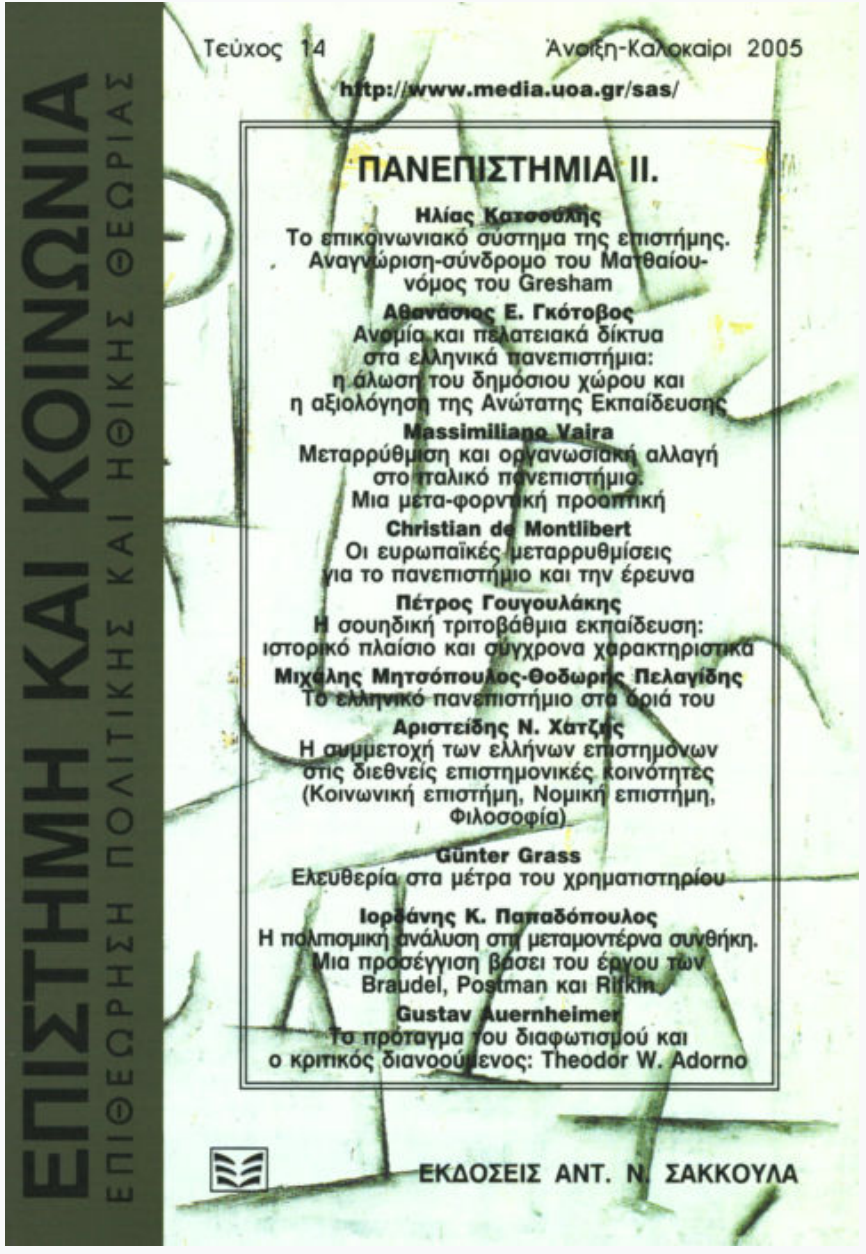

\section{Uta Gerhardt, Idealtypus. Zur methodischen Begruendung der modernen Soziologie}

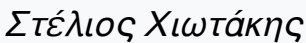

doi: $10.12681 /$ sas. 483

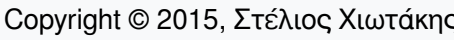

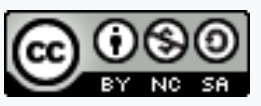

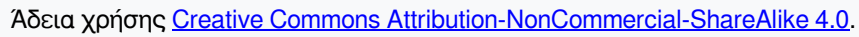

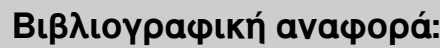

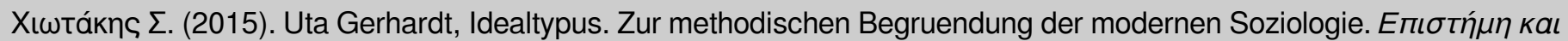

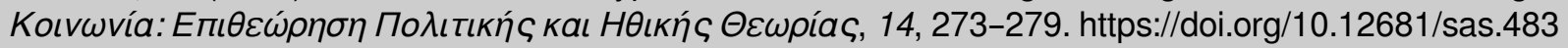


Uta Gerhardt, Idealtypus. Zur methodischen Begruendung der modernen

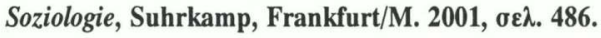

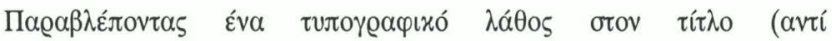

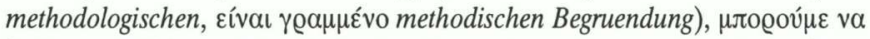

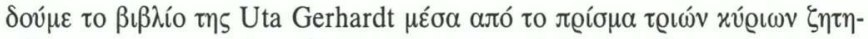

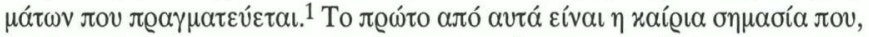

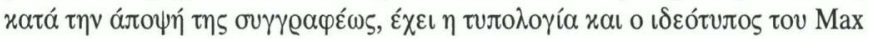

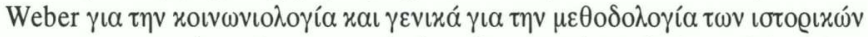

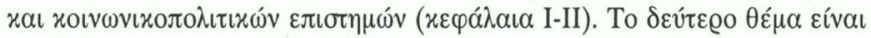

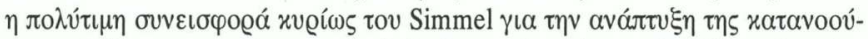

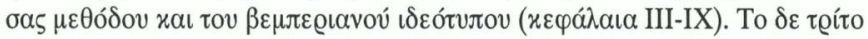

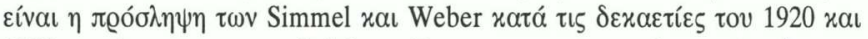

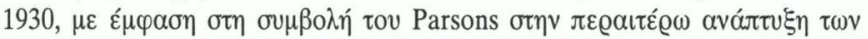

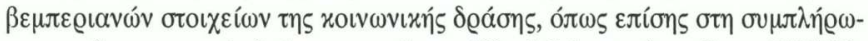

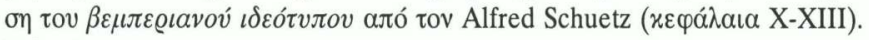

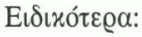

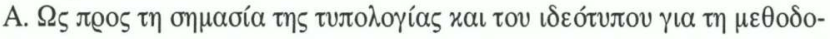

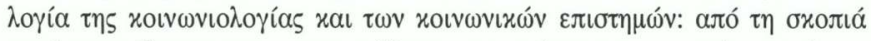

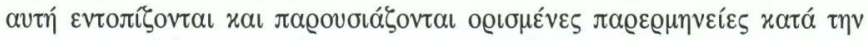

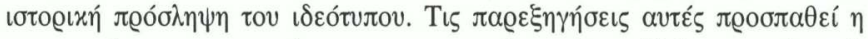

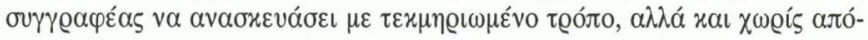

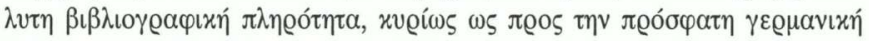

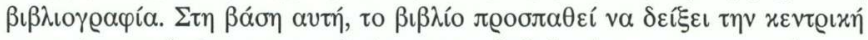

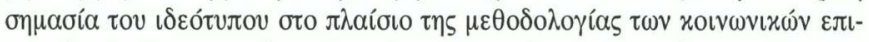

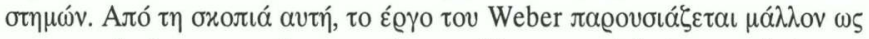

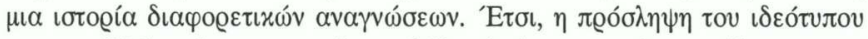

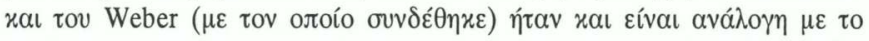

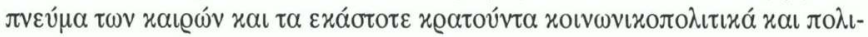

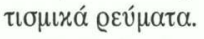

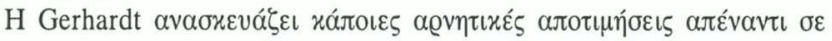

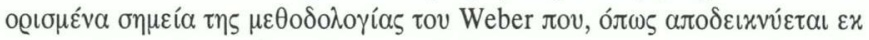

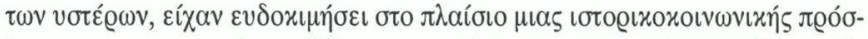

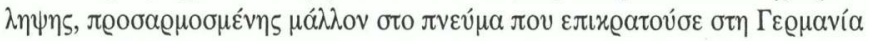

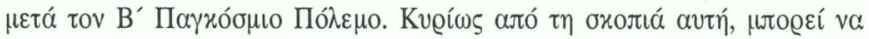

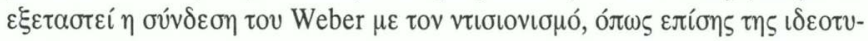

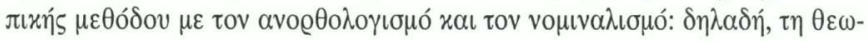




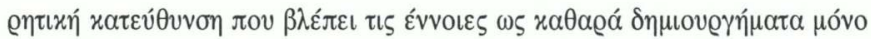

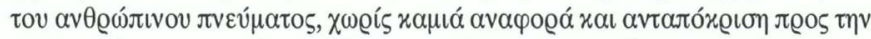

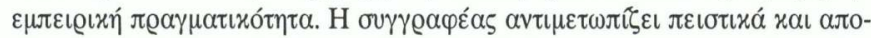

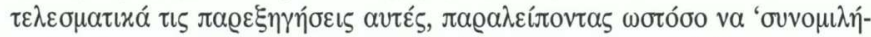

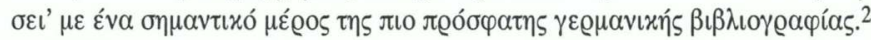

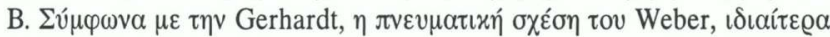

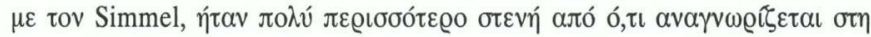

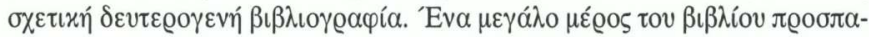

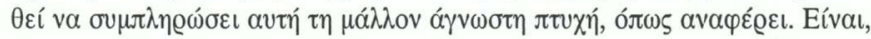

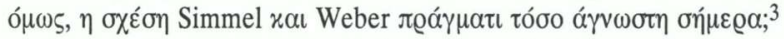

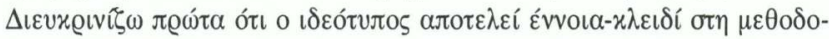

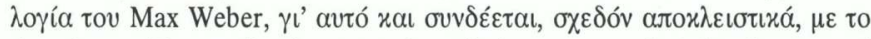

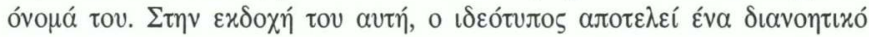

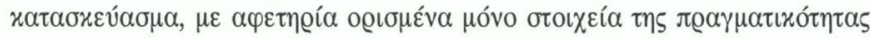

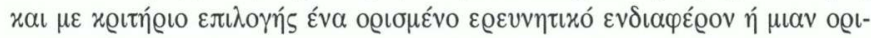

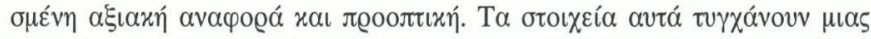

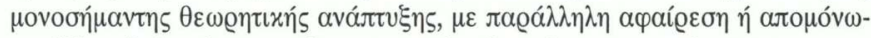

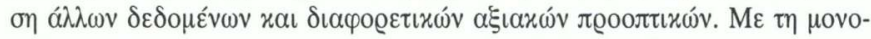

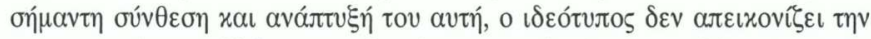

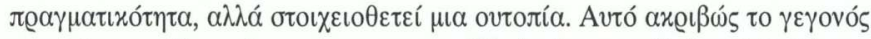

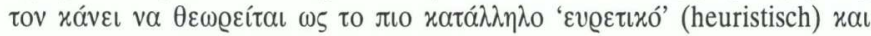

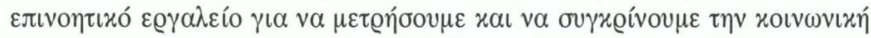

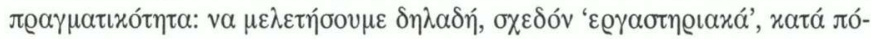

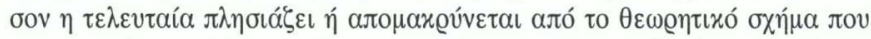

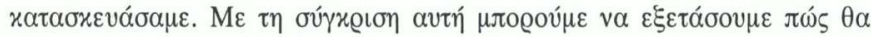

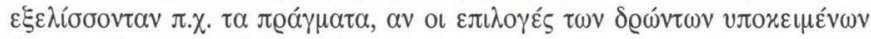

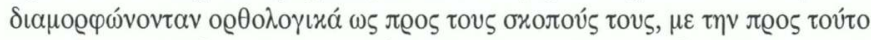

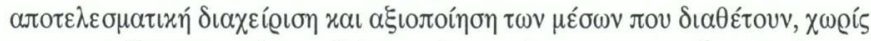

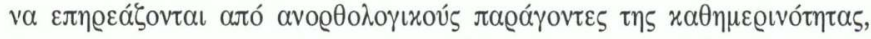

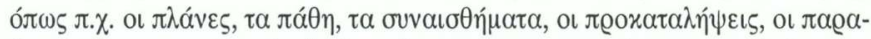

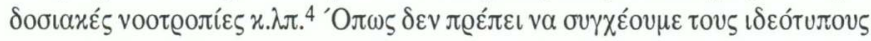

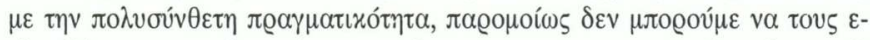

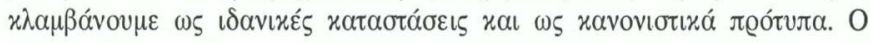

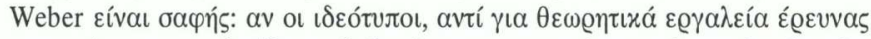

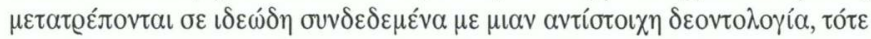

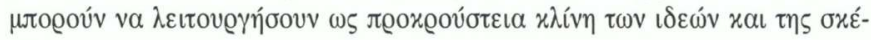
$\psi \eta \varsigma$. 


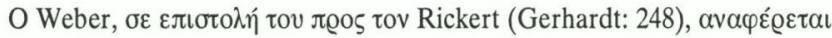

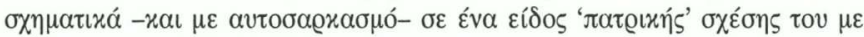

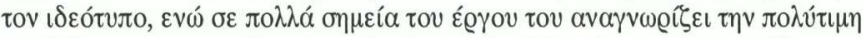

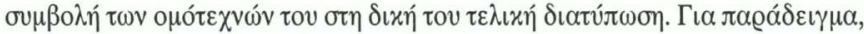

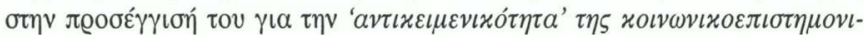

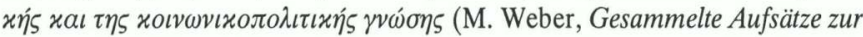

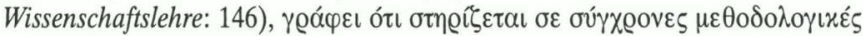

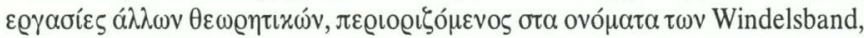

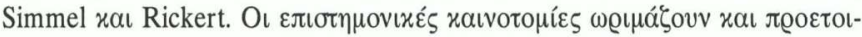

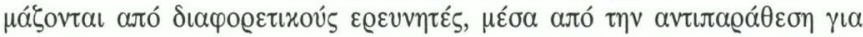

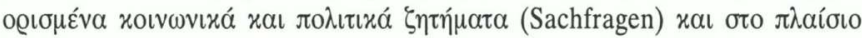

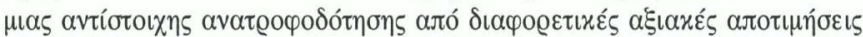

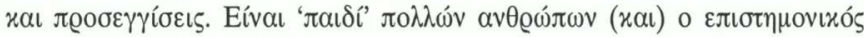

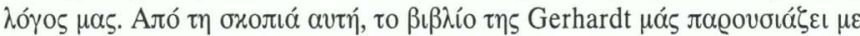

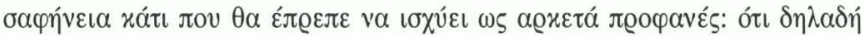

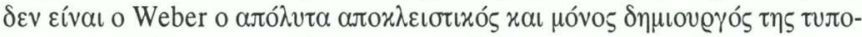

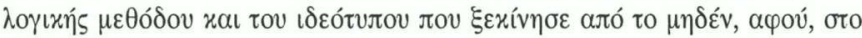

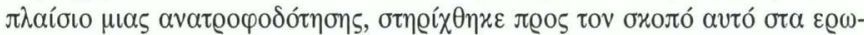

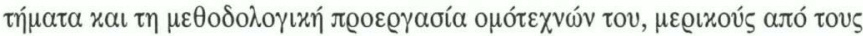

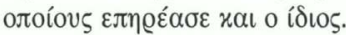

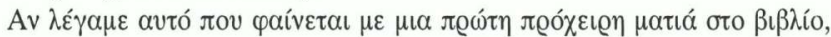

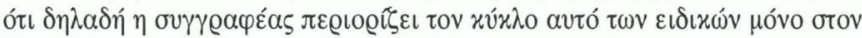

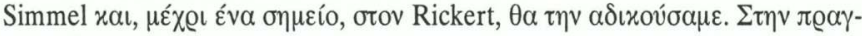

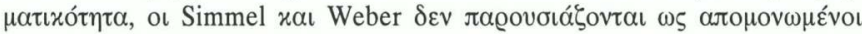

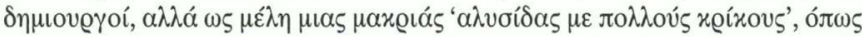

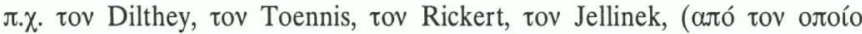

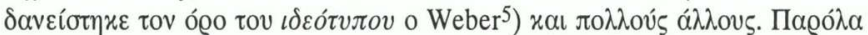

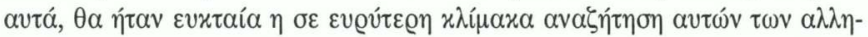

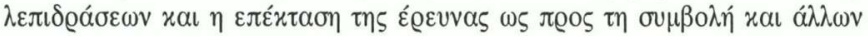

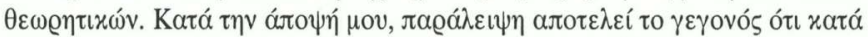

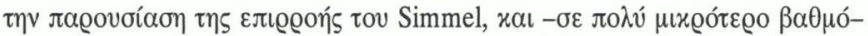

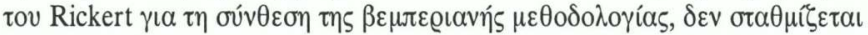

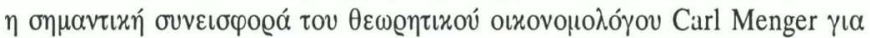

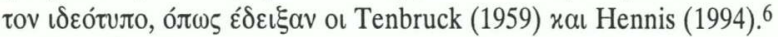

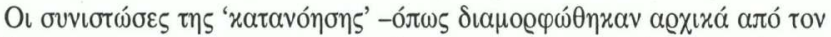

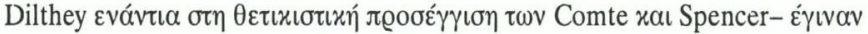

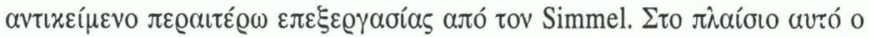




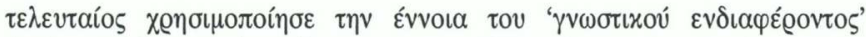

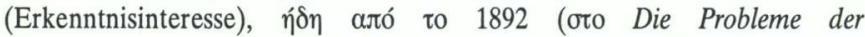

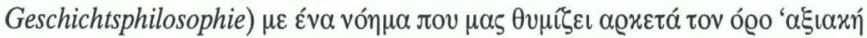

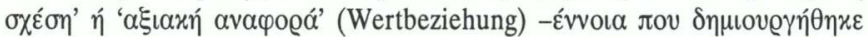

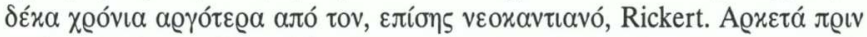

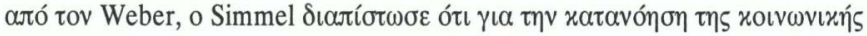

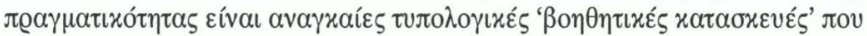

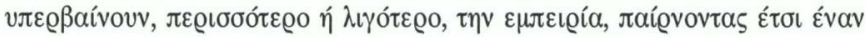

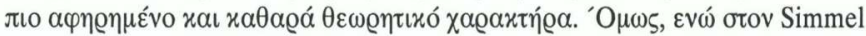

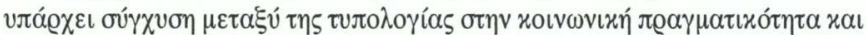

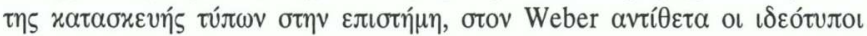

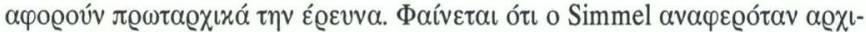

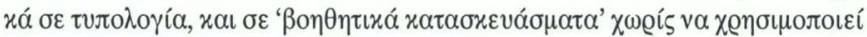

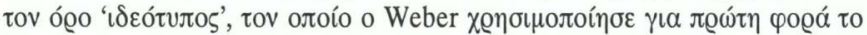

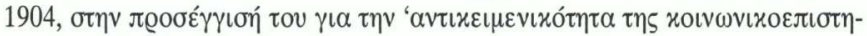

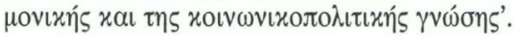

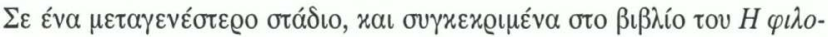

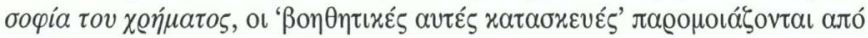

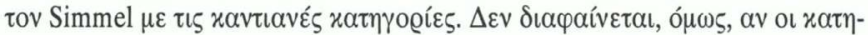

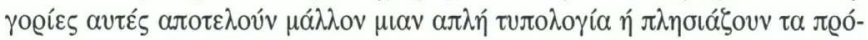

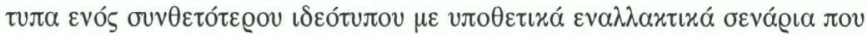

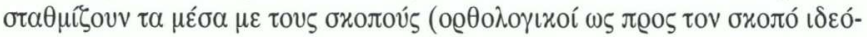

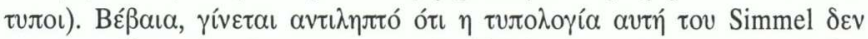

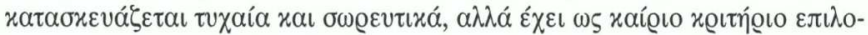

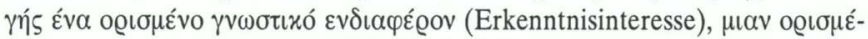

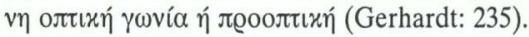

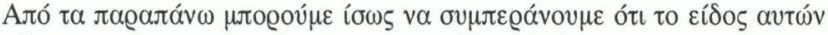

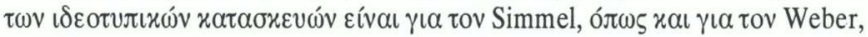

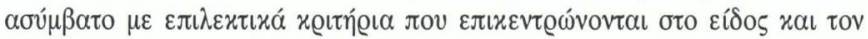

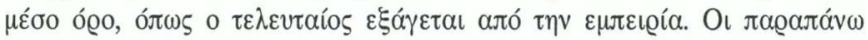

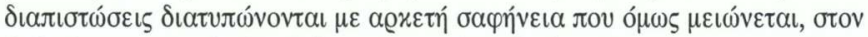

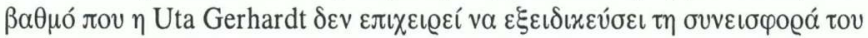

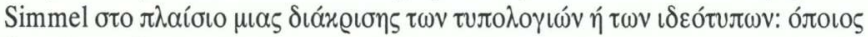

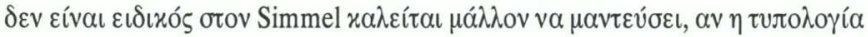

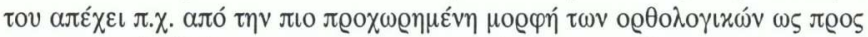

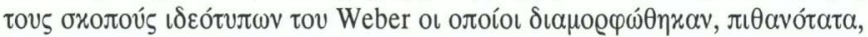

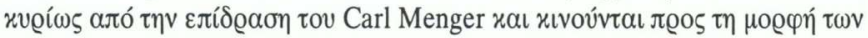




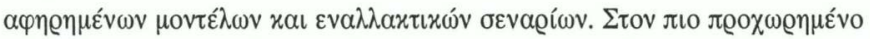

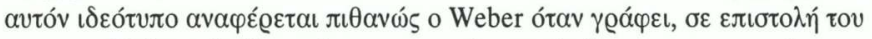

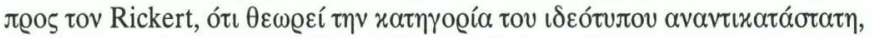

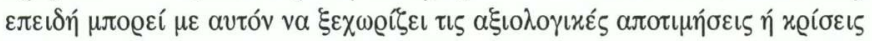

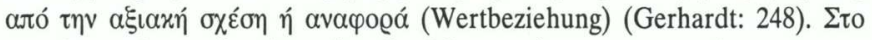

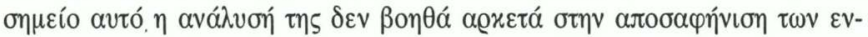

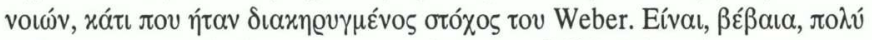

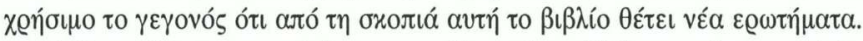

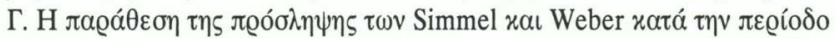

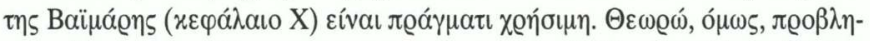

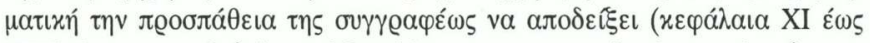

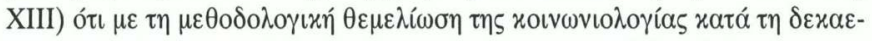

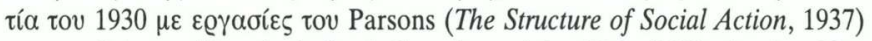

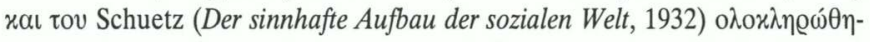

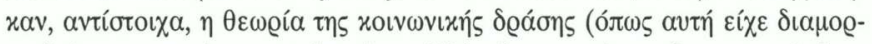

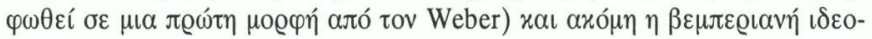

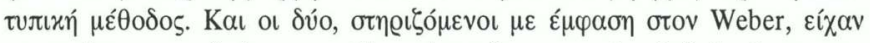

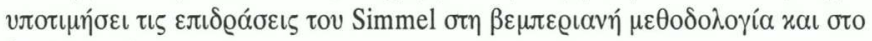

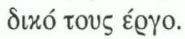

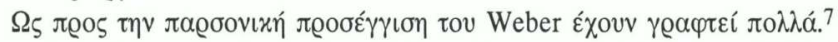

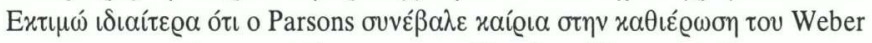

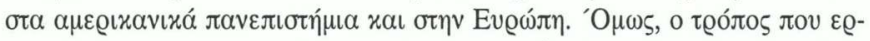

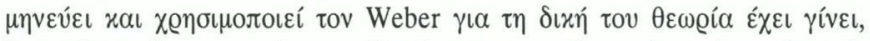

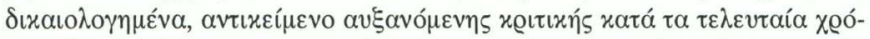

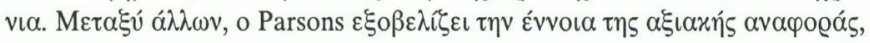

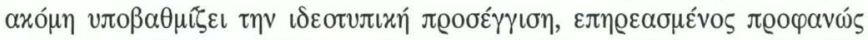

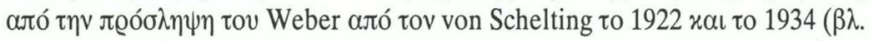

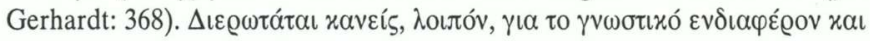

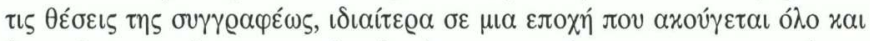

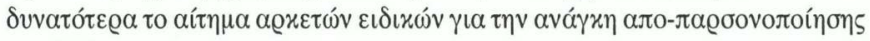
tov Weber.

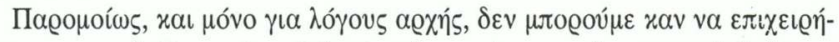

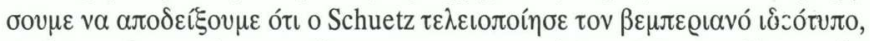

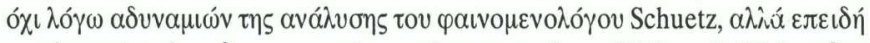

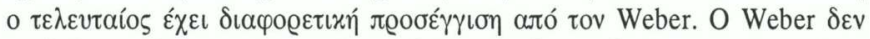

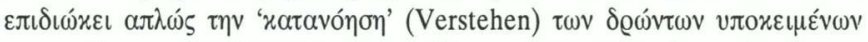

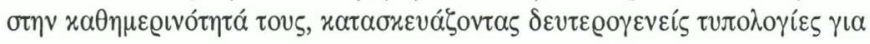




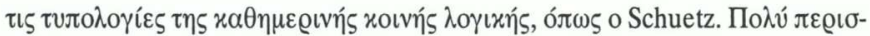

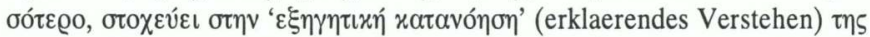

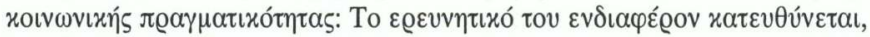

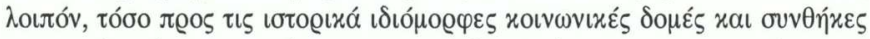

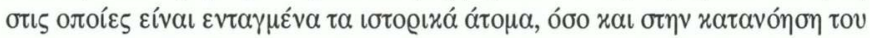

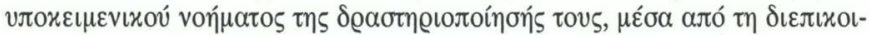
v

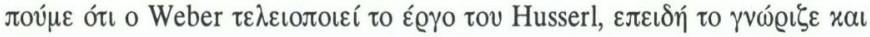

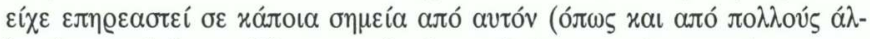

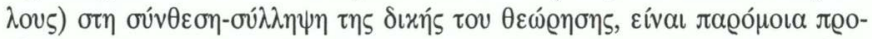

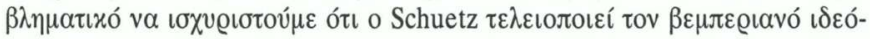

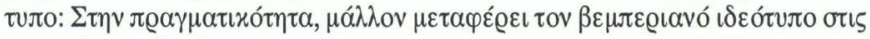

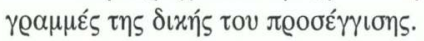

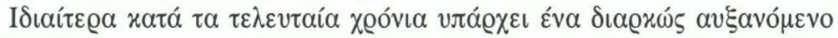

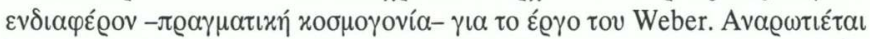

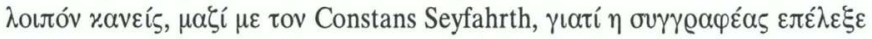

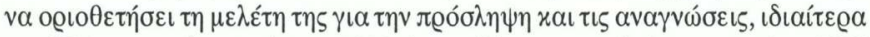

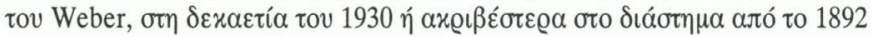

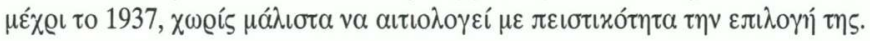

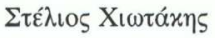

\section{$\Sigma \eta \mu \varepsilon เ(\dot{\sigma \varepsilon \varepsilon \zeta 5}$}

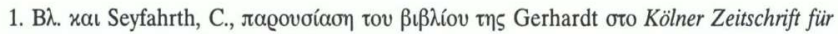

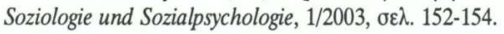

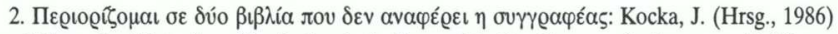

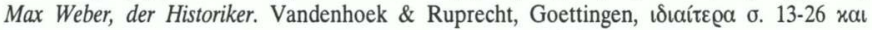
Wagner, G.-Zipprian, H. (Hrsg.,1994) Max Webers Wissenschaftslehre, Suhrkamp taschenbuch.

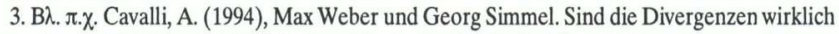
so gross?, xa Lichtblau, K. (1994) Kausalitaet oder Wechselwirkung? Max Weber und Georg

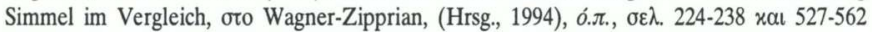
avtiotox $\alpha$. Rammstedt, O. (Hrsg., 1988). Simmel und die frühen Soziologen. Nähe und Distanz

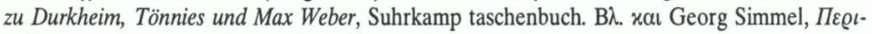

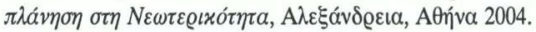

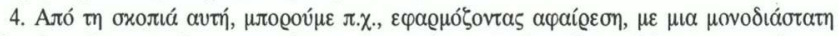

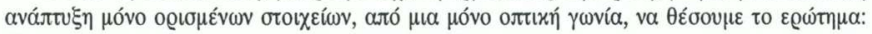

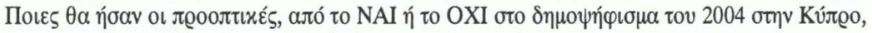

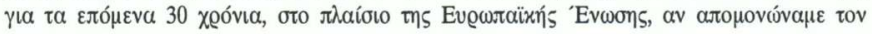




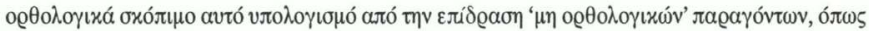

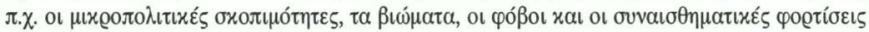

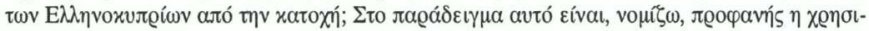

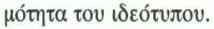

5. B $\lambda$. Gerhardt: $\sigma \varepsilon \lambda$. 248. Tenbruck, F. (1959), Die Genesis der Methodologie Max

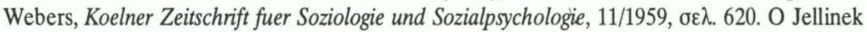

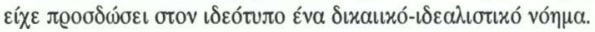

6. Hennis, W. (1994), Die volle Nuechternheit des Urteils: Max Weber zwischen Carl Menger und Gustav Schmoller. Zum hoschulpolitischen Hintergrund des Wertfreiheits-

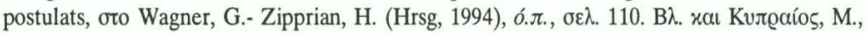

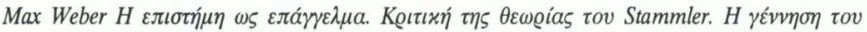

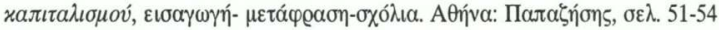

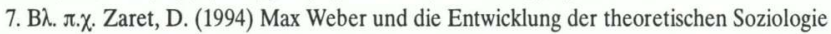

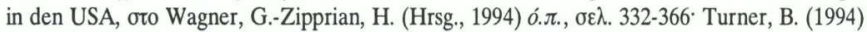
Lebensphilosophie und Handlungstheorie - Die Beziehung zwischen T. Parsons und M. Weber

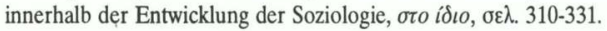

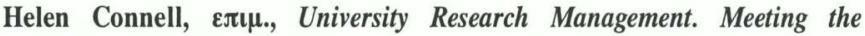

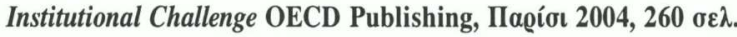

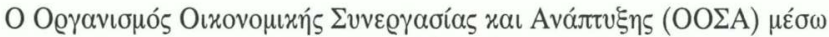

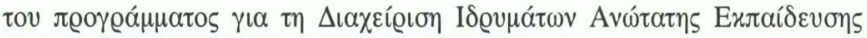
(Programme on Institutional Management in Higher Education-IMHE) $\pi \alpha-$

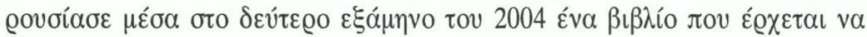

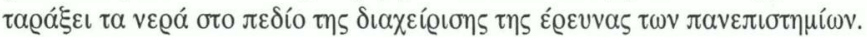

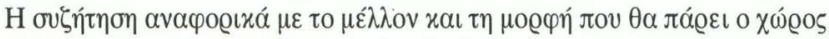

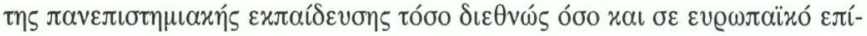

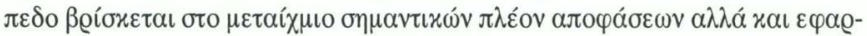

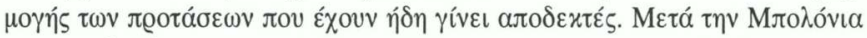

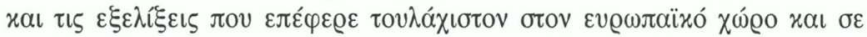

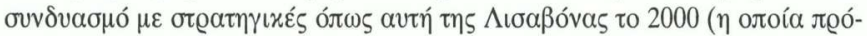

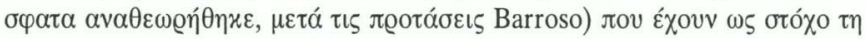

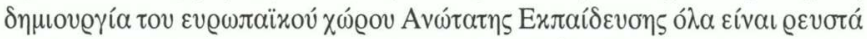

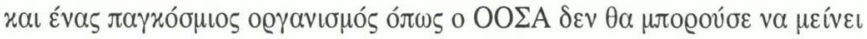

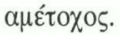

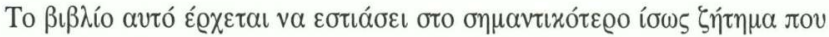

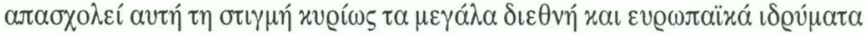

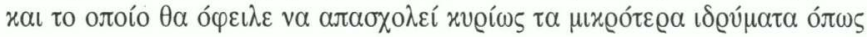

